\title{
Sex-specific lung functional changes in adult mice exposed only to second-hand smoke in utero
}

\author{
Alexandra Noël', Rui Xiao², Zakia Perveen', Hasan Zaman', Viviana Le Donne ${ }^{3}$ and Arthur Penn ${ }^{*}$
}

\begin{abstract}
Background: An increasing number of epidemiological and experimental studies have associated exposure to second-hand smoke (SHS) during pregnancy with adverse outcomes in newborns. As we have previously shown in mice, in utero exposure to SHS at critical stages of fetal development, results in altered lung responses and increased disease susceptibility upon re-exposure to irritants (SHS or ovalbumin) in adulthood. In this study, we asked whether the in utero SHS exposure alone is sufficient to alter lung structure and function in adult mice.

Methods: Pregnant BALB/c mice were exposed from days 6 to 19 of pregnancy to $10 \mathrm{mg} / \mathrm{m}^{3}$ of SHS or HEPA-filtered air. Male and female offspring ( $n=13-15 /$ group) were sacrificed at 15 weeks of age. We measured lung function with non-invasive and invasive methods, performed lung morphometric analysis on trichrome-stained lung tissue samples, and assessed lung gene expression via RNA sequencing and protein assays.

Results: In utero SHS exposure significantly increased mean linear intercept and decreased the surface area per unit volume of the lungs in both males and females, indicating perturbation in alveolar developmental processes. Tidal volume, minute volume and inspiratory capacity were significantly decreased compared with the controls only in male mice exposed in utero to SHS, suggesting that males are more sensitive than females to an SHS insult during lung development. This also suggests that in our model, lung structure changes may be necessary but are not sufficient to impair lung function. SERPINA1A, the mouse ortholog of human a1-antitrypsin, deficiency of which is a known genetic risk factor for emphysema, was down-regulated at the protein level in the in utero SHS-exposed mice. Additionally, DNMT3A protein expression was dysregulated, indicating that DNA methylation occurred in the lungs.

Conclusions: Our results indicate that in utero SHS exposure alone alters both lung function and structure well into adulthood (15 weeks) in male mice. Furthermore, lung function alterations in this model are sex-specific, with males being more susceptible to in utero SHS effects. Overall, our data suggest that in utero SHS exposure alone can predispose to adult lung diseases.
\end{abstract}

Keywords: In utero exposures, Second-hand smoke, Lung function, Lung structure, Sex specificity

\section{Background}

Since the first Surgeon General's Report on Smoking and Health in 1964 [1], tobacco use has been recognized as a leading public health concern. Currently, over 5 million deaths worldwide occur annually due to direct tobacco use, with second-hand smoke (SHS) exposures being responsible for approximately 600,000 of those

\footnotetext{
* Correspondence: apenn1@|su.edu

'Department of Comparative Biomedical Sciences, School of Veterinary

Medicine, Louisiana State University, Skip Bertman Drive, Baton Rouge 70803,

$L A$, USA

Full list of author information is available at the end of the article
}

deaths $[1,2]$. In 1994, the US EPA classified SHS as a class A carcinogen. SHS aerosols are a complex mixture of highly toxic particles and gases that contain more than 4000 different chemicals, including polynuclear aromatic hydrocarbons (PAHs), 250 cytotoxic compounds and at least 50 substances that are classified as known or possibly carcinogenic to humans, such as formaldehyde, cadmium, nickel and benzo(a)pyrene [2-4]. Annually, in the United States, over 126 million people, including pregnant women and women of childbearing age, are exposed to SHS [5]. This is in addition to the 
$10 \%$ of women who smoke during their pregnancy [6]. Thus, unborn children are a vulnerable subpopulation involuntarily exposed to cigarette smoke and SHS. It is now well documented that active smoking during pregnancy causes altered lung function, including decreased compliance and expiratory flow rates, as well as increased resistance, and increased lower respiratory diseases in the offspring [7-12]. However, few studies have investigated the contribution of in utero SHS exposures to these same outcomes. Currently, there is a growing body of epidemiological evidence showing that in utero exposures to SHS can affect fetal development and result in adverse effects ranging from low birth weight to increased disease susceptibility in adulthood [13-15].

As early as 1967, the health consequences of SHS to children, particularly on the respiratory tract, were recognized and documented [16]. More recent studies have shown that in utero exposure to environmental pollutants, including SHS, results in alterations of physical and physiological features of the fetus, as well as increased disease susceptibility in adulthood [17-20]. Studies from our lab and others have shown that in utero SHS exposure exacerbates adult responses to environmental stressors, including house dust mites, Aspergillus fumigatus and SHS [18, 21, 22]. We have previously established that in utero exposure to SHS aggravates airway hyperresponsiveness, and increases expression of chemokines, cytokines, and acute phase response genes, which results in establishment of a pro-asthmatic milieu in ovalbuminchallenged adult mice $[20,23]$. We also showed that upon re-exposure to SHS as adult, mice exposed in utero to SHS exhibited altered lung structure [21]. Overall, we have demonstrated that in utero exposure to SHS 1) elicits persistent well-documented pathophysiological and molecular changes in various adult lung disease models, upon re-exposure to an irritant as an adult, and 2) modulates responses related to lung function and structure, as well as transcriptomic alterations. Meanwhile, epidemiological studies associated in utero exposure to cigarette smoke with sustained lung deficiencies, which could lead to impaired lung function following additional postnatal exposures [8, 24-26]. Moreover, epidemiological studies have demonstrated that in utero SHS exposures are a risk factor for pulmonary diseases, including asthma, as well as for altered lung function [27, 28]. Despite those clear associations, little is known about whether in utero SHS exposure alone permanently alters lung function and/or structure in the offspring. This is due mostly to the fact the human lung is exposed to a multitude of irritants throughout life, e.g. allergens and bacteria, making the contribution of in utero SHS exposure alone on lung health challenging to assess [29-31]. Thus, there is still insufficient evidence to define the long-term contribution of in utero SHS exposure alone, as a sole or baseline factor, to modification of lung function and structure, thereby predisposing to the development of lung diseases, such as asthma, emphysema, chronic bronchitis, fibrosis or cancer [29-31]. To address this knowledge gap, in the present study we asked whether in utero SHS exposure alone, without any postnatal re-exposure to an irritant, is sufficient to alter lung structure and function in adult 15-week old mice.

\section{Methods}

\section{Animal protocols and SHS exposures}

We conducted SHS exposures on BALB/c mice (Harlan, Indianapolis, IN), as described previously [20, 21, 23]. The experimental study design is presented in Fig. 1. SHS is composed of approximately $90 \%$ sidestream smoke and $10 \%$ mainstream smoke [32]. In this study, mice were exposed to $100 \%$ sidestream smoke, which is used as a surrogate for SHS. Briefly, beginning on the $6^{\text {th }}$ day after mating, half of the mated females $(n=27)$, randomly selected, were exposed to SHS generated from 3R4F filtered research cigarettes (University of Kentucky, Lexington, KY). The SHS was mixed with HEPA-filtered air to reach a total particulate matter concentration of $10 \mathrm{mg} / \mathrm{m}^{3}$. Exposures lasted $4 \mathrm{~h}$ per day from days 6 to 19 of gestation. The SHS was generated by a 30-port cigarette smoke machine (AMESA Technologies, Geneva, Switzerland). Atmosphere samples were collected for gravimetric analysis at a flow rate of $3 \mathrm{~L} / \mathrm{min}$ throughout the experiment on a cassette holding a $25 \mathrm{~mm}$ hydrophilic glass fiber filter with a $0.7 \mu \mathrm{m}$ pore size (Millipore, AP4002500). The mass concentrations were followed and adjusted in real time using a DustTrak Aerosol Monitor 8520 (TSI Inc., Shoreview, MN, USA) previously calibrated with the SHS aerosol. The remaining mated

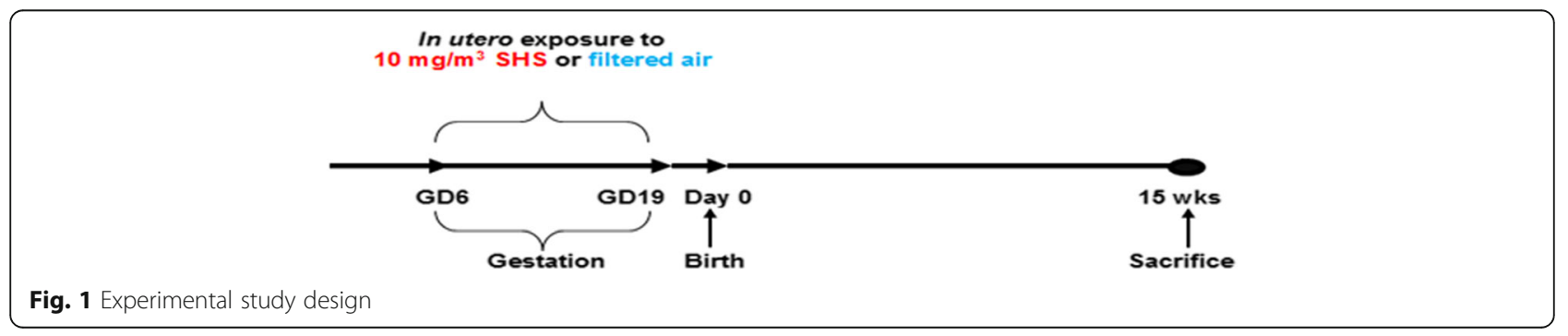


females $(n=28)$ were exposed to 100\% HEPA-filtered air. All exposures (HEPA-filtered air and SHS) occurred in $1.3 \mathrm{~m}^{3}$ dynamic chambers with approximatively 15 air changes/hour. Table 1 shows the characterization of the SHS and control HEPA-filtered air exposures. SHS-exposed female mice $(n=27)$ gave birth to 18 litters (5.39 \pm 2.4 (SD) pups/litter), with a male to female ratio of 0.60 . Air-exposed female mice $(n=28)$ gave birth to 18 litters $(5.39 \pm 2.2(\mathrm{SD}) \mathrm{pups} / \mathrm{litter})$, with a male to female ratio of 0.56. After weaning, a subgroup of these offspring was randomly distributed (4 or 5 per cage) into their respective groups: air in utero females (AF), air in utero males (AM), SHS in utero females (SF), SHS in utero males (SM). Each group contained 13 to 15 offspring (Table 2); the remaining offspring were used in other studies. From birth to sacrifice (at 15 weeks of age) mice were maintained on HEPA-filtered air ventilated racks. Mice were housed and handled in accord with the NIH Guide for the Care and Use of Laboratory Animals. All procedures and protocols were approved by the Louisiana State University Institutional Animal Care and Use Committee.

\section{Bronchoalveolar lavage cell and fluid collection}

As previously described [20], following euthanasia, we lavaged the lungs of each mouse that was not flexiVented ( $n=7-8$ per group) 2 times with $0.5 \mathrm{~mL}$ warm phosphate-buffered saline (PBS) and resuspended the centrifuged bronchoalveolar lavage (BAL) cell pellet in PBS for BAL differential counts (300 cells). Smears were stained with a modified Wright's stain. The BAL supernatant was stored at $-80{ }^{\circ} \mathrm{C}$ for subsequent analyses.

\section{Histopathology analysis of lungs}

The lungs of the mice that were not flexiVented $(n=7-$ 8 per group) were inflated and pressure-fixed $(25 \mathrm{~cm})$ with buffered formalin (10\%) administered by intratracheal instillation. We followed previously published procedures $[20,21,23]$ for sectioning and staining $5-\mathrm{mm}$ thick lung sections. We performed trichrome staining on 5-mm thick paraffin-embedded tissue sections.

Table 1 Second-hand smoke exposure characterization

\begin{tabular}{lll}
\hline Parameters & Controls (AIR) & In utero 3R4F SHS \\
\hline Mass concentration $\left(\mathrm{mg} / \mathrm{m}^{3}\right)^{\mathrm{a}}$ & - & $11.70 \pm 2.93$ \\
Number concentration $\left(\# / \mathrm{cm}^{3}\right)^{\mathrm{b}, \mathrm{c}}$ & - & 972231 \\
Mean geometric diameter $(\mathrm{nm})^{\mathrm{b}, \mathrm{c}}$ & - & $29.2 \pm 2.7$ \\
Geometric standard deviation ${ }^{\mathrm{b}, \mathrm{c}}$ & - & $2.9 \pm 0.1$ \\
Temperature $\left({ }^{\circ} \mathrm{C}\right)$ & $23.7 \pm 1.5$ & $24.4 \pm 1.7$ \\
Relative humidity $(\%)$ & $41.7 \pm 11.4$ & $40.0 \pm 13.9$ \\
\hline
\end{tabular}

Abbreviations: $S D$ standard deviation

${ }^{a}$ Average mass concentration determined gravimetrically

${ }^{b}$ Measurements made with a scanning mobility particle sizer (SMPS)

'Values reported are averages from samples taken over 9 days
Table 2 Weight at sacrifice of all experimental groups

\begin{tabular}{lll}
\hline $\begin{array}{l}\text { Experimental in utero } \\
\text { exposed groups }\end{array}$ & $n$ & Weight at 15 weeks of age $(\mathrm{g}) \pm \mathrm{SD}$ \\
\hline Air males & 13 & $28.34 \pm 1.2$ \\
SHS males & 15 & $28.07 \pm 2.4$ \\
Air females & 14 & $23.56 \pm 1.8$ \\
SHS females & 14 & $23.45 \pm 1.3$ \\
\hline
\end{tabular}

\section{Lung morphometric analysis}

Lung morphometric analysis was based on previously published procedures [33]. In brief, a grid line system with 16 (4X4) horizontal lines was overlaid on each of 40X lung micrographs. The number of times a line intercepts an alveolar wall was used to calculate mean linear intercept $\left(\mathrm{L}_{\mathrm{m}}\right)$ and surface area per unit volume (SApUV) [32]. In total, 15 sections were analyzed per sample, with $n=5$ samples per group. Images were obtained with a Nikon Eclipse E400 microscope (Nikon, Tokyo, Japan).

\section{Pulmonary function testing Whole body plethysmography}

At 15 weeks of age, we placed the mice into individual chambers of a whole body plethysmograph (Buxco, Troy, $\mathrm{NY}$ ) and measured baseline tidal and minute volumes, as previously described [20, 21, 23]. The lung responses were recorded and readings over $5 \mathrm{~min}$ were averaged for each mouse ( $n=8$ per group).

\section{flexiVent}

At 15 weeks of age, pulmonary function were also measured via an invasive method ( $n=6-7$ per group). Mice were anesthetized by a ketamine/xylazine cocktail, tracheostomized, and placed in the forced oscillation measurements flexiVent system (SCIREQ, Montreal, Canada). Measurements were accepted only if the coefficient of determination was $>0.95$. For each mouse, five measurements per parameter were averaged. At baseline, lung resistance $(\mathrm{R})$, compliance $(\mathrm{C})$ and inspiratory capacity (IC) were calculated using the single compartment model. Mice were euthanized by an intraperitoneal injection of Beuthanasia-D (Schering-Plough, NJ) following the procedure.

\section{Lung harvest and mRNA extraction}

The lungs of the mice that were not flexiVented $(n=7-8$ per group) were harvested and used for mRNA extraction. We followed previously described procedures $[20,21$, 23], including RNA sample quantity and purity assessment with a NanoDrop ND-1000 Spectrophotometer (NanoDrop, Wilmington, DE), and further assayed 1:5 dilutions of RNA samples with an Agilent 2100 BioAnalyzer and Agilent RNA 6000 Nano Series II Kits 
(Agilent Technologies, Palo Alto, CA). All samples fell into the following ranges: $260 / 280$ ratio: $1.97-2.09 ; 260 /$ 230 ratio: $2.19-2.52$; RNA concentration: $0.43-1.12 \mu \mathrm{g} / \mu \mathrm{l}$; RNA integrity number: 9.3-9.6.

\section{Gene expression analysis}

We assessed global gene expression in lungs of individual 15 -week-old male mice ( $n=4$ per group). Samples were processed by Expression Analysis (Morrisville, NC) and sequenced, by HiSeq - $2 \times 50 \mathrm{bp}-\mathrm{PE}$ sequencing, on an Illumina sequencing platform. Post-sequencing bioinformatics analysis was performed. Across all samples, the median number of actual reads was 29.9 million with 29 million on-target reads, after removal of sequencing artifacts. Our mouse lung transcriptome had a median of 16,466 genes and 31,072 isoforms that were detected. We converted RNA samples into cDNA libraries via the Illumina TruSeq Stranded mRNA sample preparation kit (Illumina \# RS-122-2103). We considered gene probes with at least 2-fold up-/down-regulation $(p<0.05)$ and false discovery rate $(\mathrm{FDR})<0.05$ to be differentially expressed. We analyzed gene expression clusters with DAVID [34].

\section{Extraction of proteins}

We extracted proteins from frozen lung tissue (stored at $-80{ }^{\circ} \mathrm{C}$ ) as described [35]. Briefly, tissues placed inside aluminum foil were snap-frozen in liquid nitrogen, mechanically broken by light hammering, and quickly placed into $2 \mathrm{~mL}$ round bottom micro-centrifuge tubes containing $300 \mu \mathrm{L}$ of RIPA lysis buffer (Santa Cruz Biotechnology, Dallas, TX, USA), and three $2.5 \mathrm{~mm}$ zirconia/silica beads (Biospec Products Inc.). Tissues were then lysed completely with the aid of Tissue Lyser II (Qiagen, Germantown, MD, USA) at $25 \mathrm{MHz}$ for $2 \mathrm{~min}$. The lysed tissue was centrifuged at $13,000 \mathrm{~g}$ for $5 \mathrm{~min}$ at $4{ }^{\circ} \mathrm{C}$. Proteins in the supernatants were aliquoted and stored at $-80{ }^{\circ} \mathrm{C}$. We used BCA protein assay kits (Thermo Scientific, Waltham, MA, USA) to determine protein concentrations in the lung supernatants.

\section{Western blotting}

We incubated $15 \mu \mathrm{g}$ of protein extracts from each of 12 lung tissues (6 controls exposed to HEPA-filtered air and 6 mice exposed to SHS) in Laemmli buffer (Bio-Rad Laboratories Inc., Hercules, CA, USA) with 2-mercaptoethanol, at $95{ }^{\circ} \mathrm{C}$ for $5 \mathrm{~min}$ in a PCR machine, and resolved protein bands by SDS-PAGE on Any $\mathrm{kD}^{\mathrm{mm}}$ Mini-PROTEAN ${ }^{\circ}$ TGX $^{\mathrm{m}}$ Gel (Bio-Rad) at $150 \mathrm{~V}$. We used a 250-10 kDa pre-stained protein ladder (Bio-Rad, Precision Plus Protein ${ }^{\mathrm{m}}$ Dual Color Standards, Cat\# 161-0374) as a standard to monitor migration of protein on the gel. Proteins resolved on the gels were transferred onto PVDF membranes (ImmobilonP, pore size of $0.45 \mu \mathrm{m}$, Millipore Inc., USA) by the TransBlot Turbo $^{\text {TM }}$ Transfer System (Bio-Rad). Antibodies to
ERK5 or MAPK7 (Cat. No. 3552) and $\beta$-actin (ACTB, Cat. No. 4967 L), as the control, were purchased from Cell Signaling Technology Inc., (Danvers, MA, USA). Antibodies to cytochrome DNMT3A (Cat No. PA-1-882), and SERPINA1A (Cat. No. PA5-1661) were obtained from Thermo-Fisher Scientific Inc., (Waltham, MA, USA). Antibodies to PHF1 (Cat. No. Ab184951) was obtained from Abcam (Cambridge, MA, USA). All antibodies were diluted in blocking buffer made with $1 \times$ Tris-Buffered-Saline (Bio-Rad) supplemented with $1 \%$ bovine serum albumin (Immucor Inc., Norcross, GA), and $0.1 \%$ Tween 20 (Bio-Rad). Immunoblots were detected with the aid of the ECL-Prime Western Blotting Detection reagent (GE Healthcare, UK). Western blot images were captured by with ChemiDoc ${ }^{\text {Th }}$ Touch imaging system (Bio-Rad). The captured images were analyzed with Image Lab 5.2 (Bio-Rad). Experiments were run in duplicate or triplicate.

\section{Statistical procedures}

Mouse weights, BALF cytology, lung function and lung morphometry were analyzed by the Student $t$-test for pairwise comparisons or by ANOVA followed by the Tukey's test for multiple comparisons. Results were considered statistically significance at $p<0.05$. We carriedout statistical analyses with the Statistical Package for the Social Sciences (SPSS, version 17.0, SPSS Inc.).

\section{Results}

In utero SHS exposure alone alters lung structure in male and female mice

We performed lung morphometric analysis on trichromestained lung tissues from SHS-exposed and air control mice to assess mean linear intercept $\left(\mathrm{L}_{\mathrm{m}}\right)$ and surface area per unit volume (SApUV), which can serve as indicators of lung tissue damage when respectively elevated and decreased [36]. Figure 2 demonstrates that in utero SHS exposure results in significantly increased $\mathrm{L}_{\mathrm{m}}$ and significantly decreased SApUV, in both male and female mice at 15 weeks of age. In utero SHS exposure significantly increased $\mathrm{L}_{\mathrm{m}}$ to $64 \mu \mathrm{m} \pm 5.9$ versus $45 \mu \mathrm{m} \pm 2.2$ for airexposed males and to $60 \mu \mathrm{m} \pm 3.7$ versus $45 \mu \mathrm{m} \pm 2.4$ for air-exposed females (Fig. 2a). Figure $2 \mathrm{~b}$ shows associated representative trichrome-stained slides of lung tissues. Airspace enlargement can be observed for SM and SF groups. Morphometric measurements of SApUV confirmed alterations in lung structure. The SApUV declined significantly for both male and female mice exposed in utero to SHS (37 \pm 1.9 for SM and $39 \pm 1.4$ for $\mathrm{SF}, 1 / \mathrm{mm}$ ) compared with their respective airexposed controls $(48 \pm 2.2$ for $\mathrm{AM}$ and $49 \pm 2.3$ for AF, 1/mm) (Fig. 2a). 


\begin{tabular}{|c|c|c|}
\hline $\begin{array}{c}\text { Experimental } \\
\text { groups }\end{array}$ & $\begin{array}{c}\text { SApUV } \\
(1 / \mathrm{mm}) \pm \text { SEM }\end{array}$ & $\begin{array}{c}M L I \\
(\mu \mathrm{m}) \pm \text { SEM }\end{array}$ \\
\hline $\begin{array}{l}\text { Air in utero } \\
\text { males }\end{array}$ & $48 \pm 2.2$ & $45 \pm 2.2$ \\
\hline $\begin{array}{l}\text { SHS in utero } \\
\text { males }\end{array}$ & $37 \pm 1.9^{*}$ & $64 \pm 5.9^{*}$ \\
\hline $\begin{array}{l}\text { Air in utero } \\
\text { females }\end{array}$ & $49 \pm 2.3$ & $45 \pm 2.4$ \\
\hline $\begin{array}{l}\text { SHS in utero } \\
\text { females }\end{array}$ & $39 \pm 1.4^{*}$ & $60 \pm 3.7^{*}$ \\
\hline
\end{tabular}

B

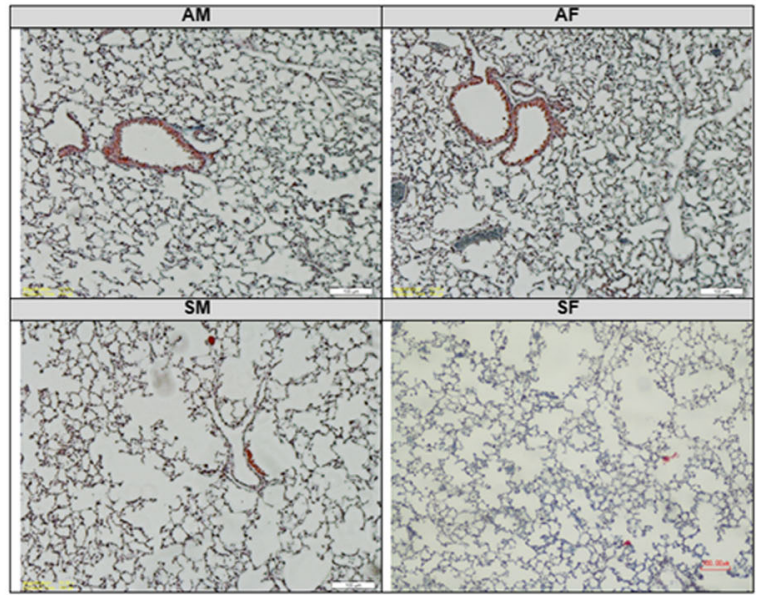

Fig. 2 In utero SHS exposure significantly increased mean linear intercept $\left(\mathrm{L}_{m}\right)$ and decreased the surface area per unit volume (SApUV) of the lungs in both males and females. a) Data are expressed as mean \pm standard error of the mean (SEM) ( $n=5$ per group). ${ }^{*} p<0.05$ statistically different from the respective control group. b) 10x magnification of representative trichrome-stained slides of lung tissue of mice show that in utero SHS increases alveolar airspace of the lungs. AM: in utero air-exposed male mice; SM: in utero SHS-exposed male mice; AF: in utero air-exposed female mice; SF: in utero SHS- exposed female mice

\section{In utero SHS exposure alone decreases lung function in male mice}

Since in utero SHS exposure alone affected lung structure, we next asked whether these structural changes impacted lung function. At 15 weeks of age, pulmonary function testing at baseline levels revealed that tidal volume $(0.191 \pm 0.05$ versus $0.156 \pm 0.04 \mathrm{~mL})$ and minute volume $(55.44 \pm 1.83$ versus $43.42 \pm 1.71 \mathrm{~mL})$, measured by whole-body plethysmography, were significantly decreased $(p<0.05)$ in male mice exposed in utero to SHS compared with their respective air controls (Fig. 3a and b). Similarly, the inspiratory capacity, measured with the flexiVent system, showed a significant decrease $(p<0.05)$ for the lungs of male mice exposed in utero to SHS $(1.08 \pm 0.01$ versus $0.90 \pm 0.07 \mathrm{~mL}$ ) (Fig. 3c). No significant differences were observed for these parameters in the female mice (Fig. 3). Since at 15 weeks of age there were no significant differences in the body weight of the mice exposed in utero to SHS or to filtered air (Table 2), the significantly reduced lung capacities (Fig. 3) that we observed in male mice exposed in utero to SHS were not due to body weight differences. In addition, we observed no indicators of pulmonary inflammation; the BALF of all groups were mainly composed of macrophages (data not shown), supporting the conclusion that decline in lung function in males was not related to obstructed airways caused by influx of leukocytes.

\section{In utero SHS exposure alone dysregulates the expression of genes and proteins in male mice}

Next, to begin to address molecular mechanisms associated with the altered lung structure and decline in lung function we observed in male mice, we conducted RNA sequencing on lung tissue. This analysis was conducted only on male mice to identify the expression of key genes dysregulated by the in utero SHS exposure, since only male mice exhibited both structural and functional changes. Figure 4 shows that in utero SHS exposure in male mice dysregulated the expression of 33 lung genes, with 21 genes being down-regulated and 12 genes up-regulated. Nine of those genes were associated with three functional clusters: 1) a fibronectin type III (FN3) cluster [fibronectin type 3 and SPRY domain containing protein ( $F s d 1 l)$, obscurin-like 1 (Obsl1), and tripartite motif-containing 46 (Trim46)]; 2) a kinase cluster [MAP-kinase activating death domain (Madd), Moloney sarcoma oncogene (Mos), and mitogen-activated protein kinase 7 (Mapk7)]; and 3) a transcription regulation cluster [DNA methyltransferase 3a (Dnmt3a), PHD finger protein 17 (Phf1), and mediator of RNA polymerase II transcription subunit 12 homolog (yeast)-like (Med12l)]. In addition, the gene Serpinala, the mouse ortholog of the human gene $\alpha 1$-antitrypsin $(A 1 A T)$, was down-regulated 7.3fold in the SM mice compared with the AM controls. The Western blots (Fig. 5) confirmed the RNA sequencing results and were obtained for both male and female mice. Expression of both DNMT3A and SERPINA1A were down-regulated, while MAPK7 and PHF1 were up-regulated in male mice exposed in utero to SHS. Similar trends were found in female mice exposed in utero to SHS, with the exception of the DNMT3A protein which was up-regulated 5.5 fold compared with the air controls. 

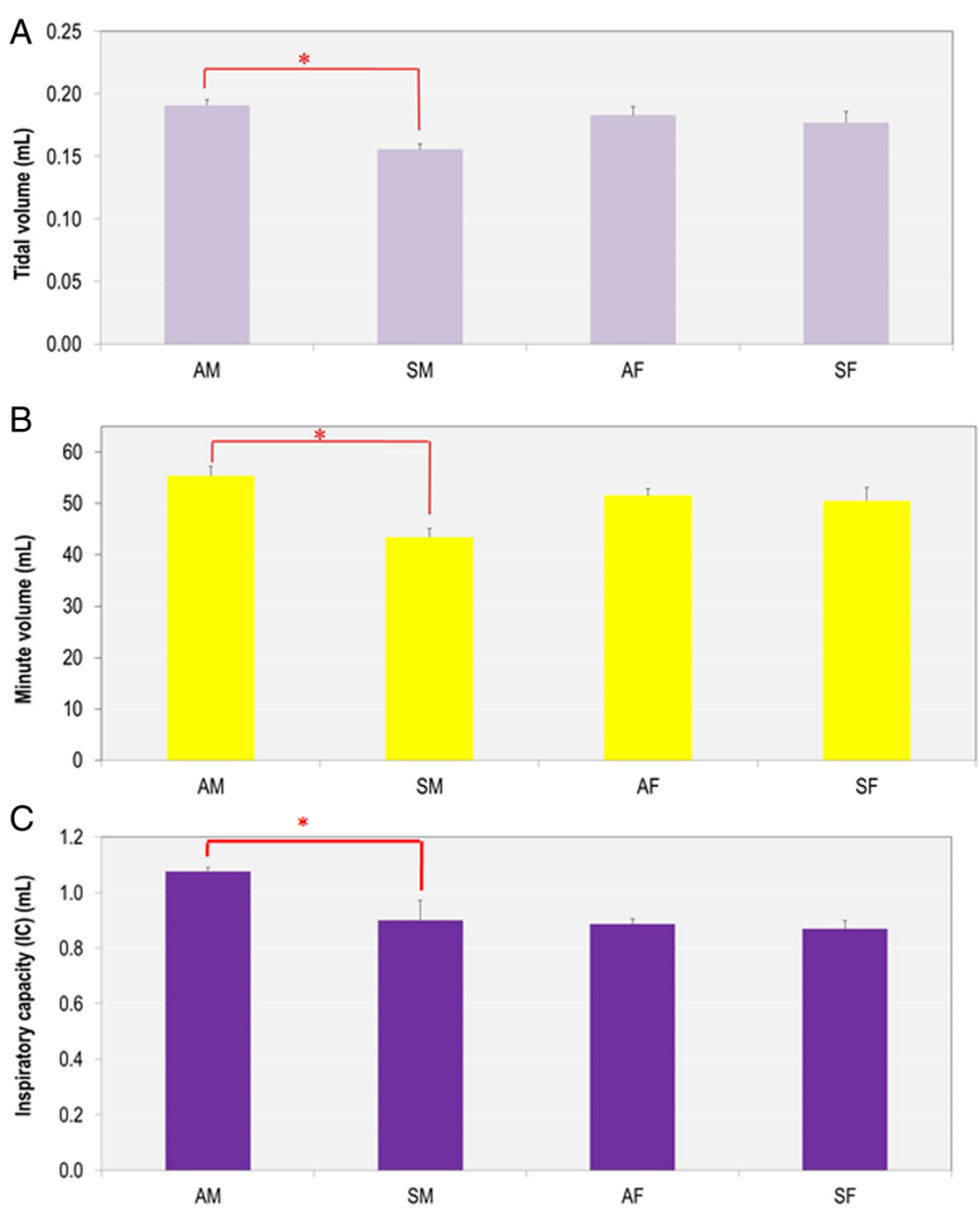

Fig. 3 In utero SHS exposure significantly decreases tidal volume, minute volume and inspiratory capacity in 15-week old male mice. a) and b) data were measured by whole body plethysmography ( $n=8$ per group), and $\mathbf{c}$ ) data were measured using a FlexiVent system ( $n=6-7$ per group). Data are expressed as mean \pm SEM. ${ }^{*} p<0.05$. AM: in utero air- exposed male mice; SM: in utero SHS- exposed male mice; AF: in utero air- exposed female mice; SF: in utero SHS-exposed female mice

\section{Discussion}

SHS is a major indoor air pollutant and increasing numbers of epidemiological and experimental studies have associated in utero exposure to SHS with adverse outcomes in newborns [2, 23, 25, 37-39]. Here we investigated whether in utero SHS exposure alone is sufficient to alter lung structure and function in adult mice. To the best of our knowledge, this is the first report of lung structural changes in adult mice exposed only to SHS in utero. We showed that in utero SHS exposure significantly increased Lm and decreased the SApUV of the lungs in both males and females (Fig. 2), indicating perturbation in alveolar developmental processes. Consequent to the lung structural alterations, the tidal volume, minute volume and inspiratory capacity were significantly decreased in male mice exposed in utero to SHS compared with the controls (Fig. 3), suggesting that males are more sensitive than females to an SHS insult during lung development. Additionally, the in utero SHS exposure dysregulated the expression of 33 genes (Fig. 4), including Serpina1a, the mouse ortholog of the human gene $A 1 A T$, with deficiency, or lower levels, of $A 1 A T$ being known genetic risk factors for emphysema. Here $A 1 A T$ was significantly down-regulated in SHS-exposed male mice. This suggests that in utero SHS exposure may predispose to emphysema development in adulthood. Furthermore, Dnmt3a, which is involved in DNA methylation, was significantly down-regulated at both gene (10 fold) and protein (2.7 fold) expression levels in SHS-exposed male mice (Figs. 4 and 5), suggesting a hypomethylated state of the lung tissue, which is known to be associated with activation of oncogenes [40-43]. In female mice, in utero exposures to SHS up-regulated the protein expression of DNMT3A 5.5 fold compared with air controls (Fig. 5), suggesting hypermethylation, which is related to silencing of tumor suppressors [40-43]. Overall, these data strongly indicate that in utero SHS exposure alone has significant persistent repercussions 


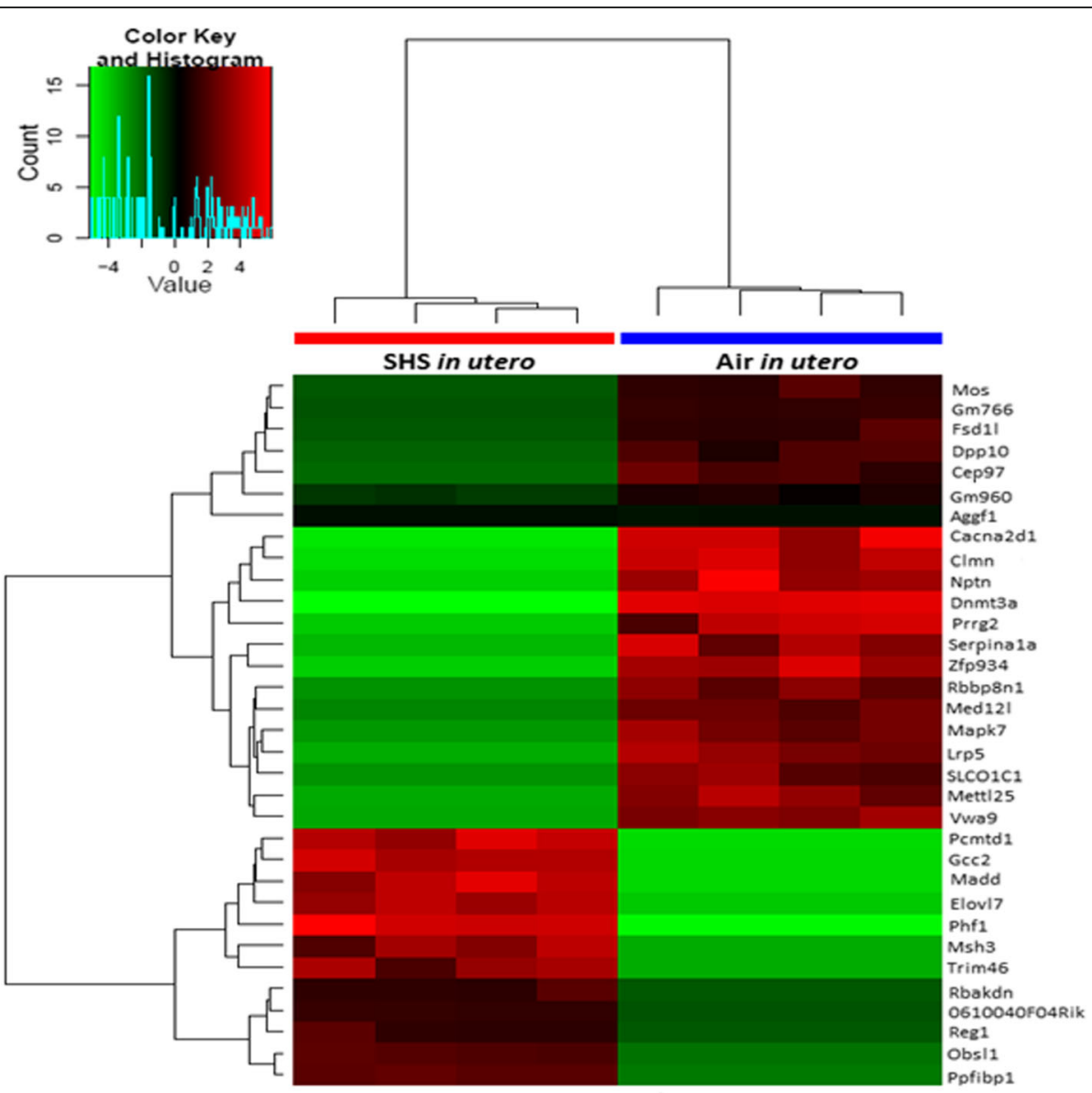

Fig. 4 In utero SHS exposure dysregulates the expression of 33 genes, including functional clusters related to fibronectin, kinase and transcription regulation in 15-week old male mice. Results are presented for global gene expression of left lung (see methods for details regarding the gene expression analysis). Data are expressed as in utero SHS-exposed mice compared with air-exposed controls (log2 ratio fold increases) $(n=4$ mice per group). Genes with at least 2-fold up-/down-regulation $(p<0.05)$ and FDR $<0.05$ were considered differentially expressed

on the respiratory system, suggesting that in utero SHS exposure can predispose to at least some incurable adult lung diseases.

Morphometric measurements determined that, following in utero SHS exposure, both male and female mice at 15 weeks of age had altered lung structure, as evidenced by elevated $L_{m}$ values, indicating 1 ) increased airspace size, and 2) diminished alveolar surface area (Fig. 2). Whether the observed SHS-induced alterations in lung structure in this mouse model are due to compromised alveolar development or to damaged septa walls is unknown [44]; however, the RNA-sequencing data suggest that in utero SHS affects extracellular matrix-associated gene expression, with the inclusion of 3 differentially expressed genes in the fibronectin type III cluster (Fig. 4). This cluster includes proteins involved in extracellular matrix remodeling (Fsd1l, Obsl1 and Trim46; Fig. 4). A previous report noted that imbalances in the production of extracellular matrix proteins, including connective tissue growth factor, collagen and fibronectin, resulted in airway remodeling [45]. Moreover, Serpina1a, the mouse ortholog of the human gene A1AT, protects the lungs against elastase activity, which hydrolyzes proteins of the extracellular matrix, and thus contributes to lung structural breakdown [46]. Serpina1a was down-regulated at the gene expression level in the in utero SHS-exposed males and at the protein level in both male and female SHS-exposed mice (Figs. 4 and 5). At 15 weeks post-in utero SHS exposure, the expression of genes involved in lung development was not significantly dysregulated; however, at this time-point, expression of genes included in the fibronectin type III cluster was significantly changed (Fig. 4). This suggests that effects of in utero SHS on genes involved in the fibronectin type III cluster are important, regarding persistence of structural and functional alterations in adulthood. Overall, our data suggest that the airspace enlargement observed in the in utero SHS-exposed mice may be consequent to lung tissue remodeling, rather than solely subsequent to impaired lung growth and development. These results are supported by epidemiological 

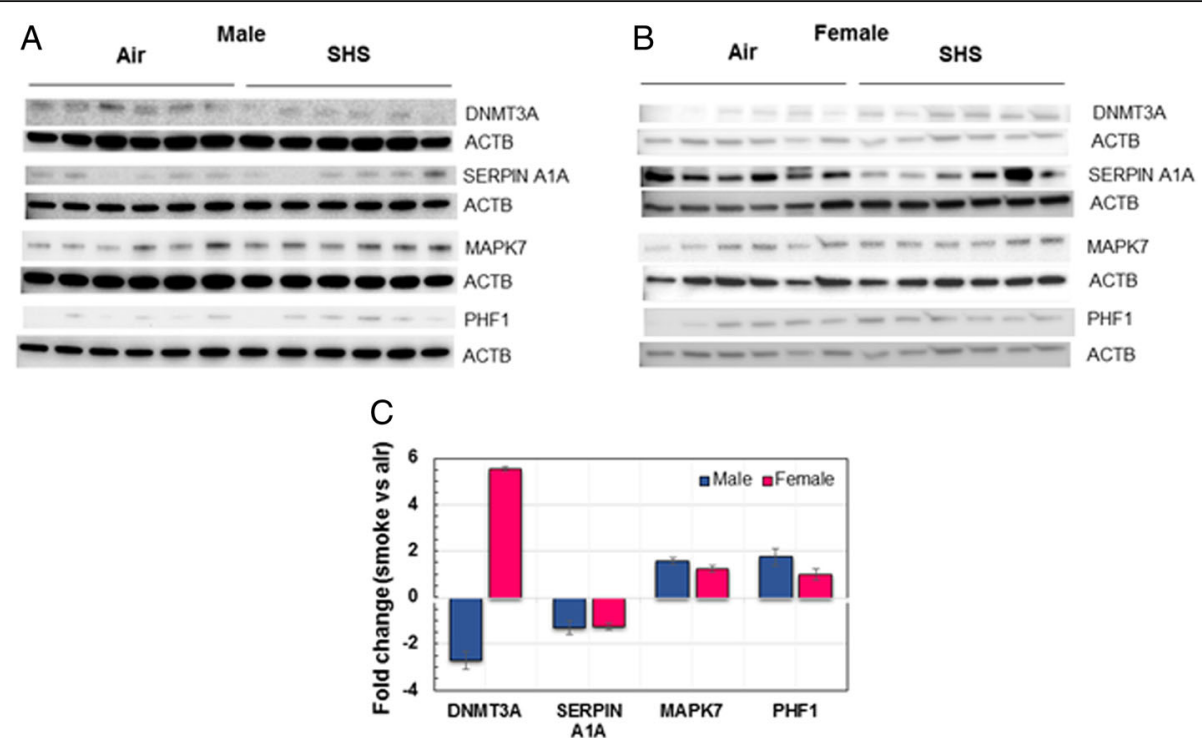

Fig. 5 In utero SHS dysregulates the protein expression of DNMT3A, SERPINA1A, MAPK7, and PHF1 in male and female mice. a) Western blots show that DNMT3A and SERPINA1A were down-regulated, whereas MAPK7 and PHF1 were up-regulated in BALB/C male mice exposed in utero to SHS versus air-treated controls. b) Western blots show that SERPINA1A was down-regulated, whereas DNMT3A and MAPK7 were up-regulated in BALB/c female mice exposed in utero to SHS versus air-treated controls. c) Mean densitometry \pm SEM results showing fold change of treated mice versus controls for the proteins analyzed

studies and animal models, where it was previously shown that in utero cigarette smoke, as well as SHS, exposures affect the lungs of the offspring in terms of reduced growth, as well as enlarged alveoli that are present in fewer numbers (hypoalveolarization) [10, 25, 47-49]. Hence, in line with previous published reports, our study shows that in utero SHS exposure alone is a direct cause of alveolar structural defects, and therefore may increase the risk of developing respiratory diseases, including obstructive pulmonary diseases, e.g. emphysema, later in life.

Our study also showed that 15-week old male mice exposed in utero to SHS had significantly decreased lung capacities, including tidal and minute volumes, as well as inspiratory capacity (Fig. 3). These decrements in lung function seem to be secondary to changes in the lung architecture, as suggested by previous studies where in utero cigarette smoke-induced lung structural alterations impaired lung function by restricting airflow in small conducting airways [10, 25, 47-49]. In our model, it is unlikely that restricted airflow is responsible for the decreases in lung volumes, since in utero SHS had no significant effect on respiratory system resistance or Newtonian resistance (resistance of the conducting airways) at 15 weeks of age (data not shown). Since in utero SHS exposure alone significantly affected the lungs' geometrical architecture, measured by alveolar airspace enlargement (Fig. 2), and gene and protein expression changes were largely associated with matrix airwayremodeling (Figs 4 and 5) in both male and female mice, with significant decline in lung function observed only in male mice (Fig. 3), the data suggest that changes in lung function may only be indirectly associated with lung structural damage. In fact, decline in lung function is multifactorial $[50,51]$ and our data suggest that lung structural changes may be necessary, but not sufficient, to impair lung function. Since all SHS fetuses were exposed simultaneously in the same chamber, these results also suggest that male mice are more susceptible than female mice to in utero SHS-induced damage, and that sex differences during lung development may play a pivotal role in healthy pulmonary function.

It is well recognized that for many mammalian species, including mice and humans, critical factors in lung development, including surfactant production and fetal breathing, are events beginning earlier in the lung maturation process of female fetuses compared with males [52-56]. Lung surfactant synthesis provides the pulmonary phenotype with adequate air flows, resistance and compliance, and thus plays a key role in optimal pulmonary function and lung homeostasis [56-60]. This suggests that the synthesis of surfactant occurring at an earlier developmental time point in females may protect the lungs against environmental insults, such as SHS, with regard to lung function. Epidemiological studies support this sex bias, with females being preferentially protected from early lung environmental irritants. The prevalence for wheeze and asthma is higher in boys than in girls [61-65]. These findings correlate with results of a previous study from our laboratory showing that male mice exposed in utero to SHS exhibited enhanced 
asthmatic responses following ovalbumin treatment compared with their female counterparts at 23 weeks of age [23]. Whether there is potential for lung recovery following in utero SHS exposure cannot be determined from our study since we only analyzed one time-point. In accordance, however, with the results of the present study, epidemiological evidence showed declines in lung function in offspring exposed in utero to cigarette smoke or SHS in childhood [8, 66-73]. These declines were sustained until early adulthood (21 years) in males [74]. This suggests that even though there may be some lung recovery, in utero cigarette smoke or SHS pulmonary effects persist into childhood and early adulthood. This study provides additional data demonstrating that lung function alterations that are sustained through early adulthood seem to be sex-specific, with males being more susceptible than females to in utero SHS effects; thus, potentially increasing the risk of males to develop respiratory diseases, including restrictive lung diseases.

Overall, we showed that even at 15 weeks of age, the effects of in utero SHS exposure can be seen in terms of altered lung structure and function, as well as altered gene and protein expression in male mice (Figs 2, 3, 4 and 5). The exact mechanisms linking the in utero SHS exposure to those adverse lung effects in adulthood are unknown; however, it is widely recognized that several types of environmental exposures, including air pollution [75], maternal diet [76], and cigarette smoke [77], induce epigenetic alterations that could impact lung development, as well as lung repair following acute injury [78]. Epigenetic mechanisms can modify the epigenome in a transitory manner or permanently into adulthood [79]. DNA methylation regulates gene expression through an epigenetic silencing mechanism and is involved in tumorigenesis by influencing, among others, the expression of oncogenes or tumor suppressor genes [41]. DNA (Cytosine-5-)-Methyltransferase 3 Alpha (Dnmt3a), an enzyme that catalyzes the transfer of methyl groups to specific CpG structures in DNA, is responsible for de novo DNA methylation, and thus that plays a central role in this mechanism [74]. The methylation status of DNA can either be hyper- or hypomethylated, although global DNA hypomethylation and specific locus hypermethylation frequently co-occur in human cancers [40, 42]. Numerous studies [80-83] showed that DNA methylation has roles in both early and late stages of tumorigenesis. In early stages, increased levels of DNA methylation lead to hypermethylation of tumor suppressor genes and thus, facilitate tumor initiation. In late stages, decreased levels of DNA methylation lead to hypomethylation of oncogenes, which promotes cancer progression [43]. Our RNA-sequencing results, confirmed by protein expression (Figs. 4 and 5), indicate that in utero SHS exposure alone significantly down-regulated (10.4 fold change at the gene level and 2.7 fold change at the protein level; Figs. 4 and 5) the expression of Dnmt3a in males, which suggests the possibility of DNA hypomethylation of other lung genes. This hypomethylation finding is supported by an epidemiological study conducted by Breton et al. [77] that used buccal and aerodigestive tissue cells (as surrogates for lung cells) of children exposed in utero to cigarette smoke and showed that this exposure resulted in significantly decreased global methylation, i.e. hypomethylation, as well as gene-specific DNA methylation alterations [77]. Global DNA hypomethylation is associated with development of cancer [84], including lung cancer, which has been associated with Dnmt3a deficiency in mice $[85,86]$. Furthermore, in our study, while in utero SHS-exposed male mice exhibited down-regulation of the DNMT3A protein (2.7 fold), female mice that underwent the same treatment showed up-regulation of this protein by 5.5 fold (Fig. 5). In a previous study, it was observed that methylation levels can be influenced by sex, although no mechanisms have been proposed [40]. As mentioned previously, it is well known that both types of alteration are associated with tumor formation, with hypomethylation status being associated with activation of oncogenes and hypermethylation with silencing of tumor suppressors [40]. Thus, in addition to our results, there is increasing evidence for epigenetic effects of in utero SHS exposure alone on lung development with persistence into adult life, and this may predispose to respiratory morbidity, including lung cancer [39].

\section{Limitations}

One limitation of this study is that RNA-sequencing was not performed on female mice, whose in utero SHSexposed group exhibited only significant structural differences compared with controls. Although RNAsequencing is a powerful tool to understand the transcriptome of cells under specific conditions, it can be very difficult to detect differences between control and treatment groups when the treatment (or insult) occurred 15 weeks earlier, even though the physiological responses are significant. We have previously showed that upon re-exposure to SHS as adults, mice exposed in utero to SHS exhibited altered lung structure and dysregulation of some genes, as detected by microarray assays [21]. Since only male mice exhibited both structural and functional changes in this study, we conducted RNA-sequencing to add valuable molecular mechanism insights for those significant differences. Therefore, based on the RNA sequencing results obtained in male mice, we analyzed the protein expression change of key affected molecules to further explore the molecular mechanisms in both sexes. Changes at the protein level are sensitive and were mostly consistent (Fig. 5) between males and females. Thus, in this study, for the female 
mice, we used protein expression as a proxy to obtain a better understanding of the molecular signatures imprinted by in utero SHS.

Another possible limitation of this study is the fact that mice were sacrificed at only one time-point. As mentioned previously, whether there is potential for lung recovery or whether lung tissue remodeling is more important than impaired growth and development following in utero SHS exposure cannot be determined from our study since we only analyzed the lungs 15 weeks postexposure. It is important, however, to bear in mind that the objective of this study was to investigate whether in utero SHS exposure alone, without any postnatal reexposure to an irritant, is sufficient to alter lung structure and function in adult 15-week old mice. Studies are currently ongoing in our laboratories to investigate in utero and neonatal developmental effects induced by SHS, hookah smoke and electronic cigarette vapor.

\section{Conclusions}

This study shows that in utero SHS exposure alone induces a wide range of effects on the developing lung. These changes persist in adult male mice at least through 15 weeks of age. Alterations included changes in lung structure and function, accompanied by dysregulation of genes and proteins involved in extracellular matrix-related airway remodeling and DNA methylation. Our findings also indicate that male mice may be more susceptible than female mice to insults occurring during lung development. Overall, this study provides baseline data indicating that in utero SHS exposure alone imprints the developing lung for potential lifelong sequelae that predispose the lung to adult obstructive and restrictive respiratory diseases, as well as lung cancer. More research is needed to provide insight on the contribution of in utero SHS exposures to the pathophysiology of emphysema and lung cancer development.

\section{Abbreviations \\ ACTB: $\beta$-actin; AF: Air in utero females; AM: Air in utero males; BAL: Broncho- alveolar lavage; BALF: Broncho-alveolar lavage fluid; EPA: Environmental Protection Agency; FDR: False discovery rate; Lm: Mean linear intercept; PAH: Polynuclear aromatic hydrocarbon; qRT-PCR: Quantitative real-time polymerase chain reaction; SApUV: Surface area per unit volume; SD: Standard deviation; SEM: Standard error of the mean; SF: SHS in utero females; SHS: Second-hand smoke; SM: SHS in utero males; WHO: World Health Organization}

\section{Acknowledgement}

The authors thank Ms. Lisa R. Peterson of the Louisiana State University School of Veterinary Medicine for excellent technical assistance.

\section{Funding}

This study was supported by a grant (AP) from the Louisiana Governor's Biotechnology Initiative GBI-BOR\#013. AN was a recipient of a post-doctoral fellowship from the Fonds de Recherche Québec Santé (FRQS).

\section{Availability of data and materials}

The datasets analyzed during the current study are available from the corresponding author on reasonable request.

Authors' contributions

AN, RX and AP designed the study. AN, RX, ZP, HZ, and VLD carried out the assays and assisted with data analysis. The manuscript was drafted by AN and revised by AP. All authors approved the final manuscript.

\section{Competing interests}

The authors declare that they have no competing interests.

\section{Consent for publication}

Not applicable.

Ethics approval and consent to participate

Mice were housed and handled in accord with the NIH Guide for the Care and Use of Laboratory Animals. All procedures and protocols were approved by the Louisiana State University Institutional Animal Care and Use

Committee (Protocol \#14-084)

\section{Publisher's Note}

Springer Nature remains neutral with regard to jurisdictional claims in published maps and institutional affiliations.

\section{Author details}

${ }^{1}$ Department of Comparative Biomedical Sciences, School of Veterinary Medicine, Louisiana State University, Skip Bertman Drive, Baton Rouge 70803, LA, USA. ${ }^{2}$ Department of Anesthesiology, Columbia University Medical Center, 622 West 168th Street, New York 10032, NY, USA. ${ }^{3}$ Translational Medicine and Comparative Pathobiology, R\&D Platform Technology and Science, GlaxoSmithKline, Park Road, Ware SG12 ODP, UK.

Received: 16 February 2017 Accepted: 17 May 2017

Published online: 27 June 2017

\section{References}

1. U.S. Department of Health, Education, and Welfare. Smoking and Health-Report of the advisory committee of the Surgeon General of the Public Health Service. Public Health Service Publication No. 1103, Washington, DC, 20402; 1964.

2. World Health Organization (WHO). Media Centre Tobacco Fact Sheet $N^{\circ}$ 339. Updated May 2014. www.who.int/mediacentre/factsheets/fs339/en/. Accessed 31 Jan 2017.

3. Liu Y, Di YP. Effects of second hand smoke on airway secretion and mucociliary clearance. Front Physiol. 2012;3:342.

4. Robinson AB, Stogsdill JA, Lewis JB, Wood TT, Reynolds PR. RAGE and tobacco smoke: insights into modeling chronic obstructive pulmonary disease. Front Physiol. 2012;3:301.

5. Menzies D. The case for a worldwide ban on smoking in public places. Curr Opin Pulm Med. 2011;17:116-22.

6. Centers for Disease Control and Prevention (CDC). CDC- Fact Sheet-Adult Cigarette Smoking in the United States_-Smoking \& Tobacco Use. 2014 https:// www.cdc.gov/tobacco/data_statistics/fact_sheets/fast_facts/. Accessed 31 Jan 2017.

7. Tager IB, Hanrahan JP, Tosteson TD, Castile RG, Brown RW, Weiss ST, Speizer FE. Lung function, pre- and post-natal smoke exposure, and wheezing in the first year of life. Am Rev Respir Dis. 1993;147:811-7.

8. Cunningham J, Dockery DW, Speizer FE. Maternal smoking during pregnancy as a predictor of lung function in children. Am J Epidemiol. 1994;139:1139-52.

9. Brown RW, Hanrahan JP, Castile RG, Tager IB. Effect of maternal smoking during pregnancy on passive respiratory mechanics in early infancy. Pediatr Pulmonol. 1995;19:23-8.

10. Lodrup-Carlsen KC, Jaakkola JJ, Nafstad P, Carlsen KH. In utero exposure to cigarette smoking influences lung function at birth. Eur Respir J. 1997;10:1774-9.

11. Milner AD, Marsh MJ, Ingram DM, Fox GF, Susiva C. Effects of smoking in pregnancy on neonatal lung function. Arch Dis Child Fetal Neonatal Ed. 1999:80:F8-F14.

12. Sekhon HS, Keller JA, Benowitz NL, Spindel ER. Prenatal nicotine exposure alters pulmonary function in newborn rhesus monkeys. Am J Respir Crit Care Med. 2001;164:989-94. 
13. Ashford KB, Hahn E, Hall L, Rayens MK, Noland M, Ferguson JE. The effects of prenatal secondhand smoke exposure on preterm birth and neonatal outcomes. J Obstet Gynecol Neonatal Nurs. 2010;39:525-35.

14. Leonardi-Bee J, Britton J, Venn A. Secondhand smoke and adverse fetal outcomes in nonsmoking pregnant women: a meta-analysis. Pediatrics. 2011;127:734-41.

15. Evlampidou I, Bagkeris M, Vardavas C, Koutra K, Patelarou E, Koutis A, Chatzi $L$, Kogevinas M. Prenatal second-hand smoke exposure measured with urine cotinine may reduce gross motor development at 18 months of age. J Pediatr. 2015;167:246-52.

16. Cameron P. The presence of pets and smoking as correlates of perceived disease. J Allergy. 1967;40:12-5.

17. Singh SP, Barrett EG, Kalra R, Razani-Boroujerdi S, Langley RJ, Kurup V, Tesfaigzi $Y$, Sopori ML. Prenatal cigarette smoke decreases lung CAMP and increases airway hyperresponsiveness. Am J Respir Crit Care Med. 2003;168:342-7.

18. Singh SP, Mishra NC, Rir-Sima-Ah J, Campen M, Kurup V, RazaniBoroujerdi S, Sopori ML. Maternal exposure to secondhand cigarette smoke primes the lung for induction of phosphodiesterase-4D5 isozyme and exacerbated Th2 responses: rolipram attenuates the airway hyperreactivity and muscarinic receptor expression but not lung inflammation and atopy. J Immunol. 2009;183:2115-21.

19. Singh SP, Gundavarapu S, Smith KR, Chand HS, Saeed Al, Mishra NC, Hutt J, Barrett EG, Husain M, Harrod KS, Langley RJ, Sopori ML. Gestational exposure of mice to secondhand cigarette smoke causes bronchopulmonary dysplasia blocked by the nicotinic receptor antagonist mecamylamine. Environ Health Perspect. 2013;121:957-64.

20. Penn AL, Rouse RL, Horohov DW, Kearney MT, Paulsen DB, Lomax L. In utero exposure to environmental tobacco smoke potentiates adult responses to allergen in BALB/c mice. Environ Health Perspect. 2007;115:548-55.

21. Xiao R, Perveen Z, Paulsen D, Rouse R, Ambalavanan N, Kearney M, Penn AL. In utero exposure to second-hand smoke aggravates adult responses to irritants: adult second-hand smoke. Am J Respir Cell Mol Biol. 2012:47:843-51.

22. Raherison C, Penard-Morand C, Moreau D, Caillaud D, Charpin D, Kopferschmitt C, Lavaud F, Taytard A, Maesano IA. Smoking exposure and allergic sensitization in children according to maternal allergies. Ann Allergy Asthma Immunol. 2008;100:351-7.

23. Xiao R, Perveen Z, Rouse RL, Le Donne V, Paulsen DB, Ambalavanan N, Penn $\mathrm{AL}$. In utero exposure to second-hand smoke aggravates the response to ovalbumin in adult mice. Am J Respir Cell Mol Biol. 2013;49:1102-9.

24. Cunningham J, O'Connor GT, Dockery DW, Speizer FE. Environmental tobacco smoke, wheezing, and asthma in children in 24 communities. Am J Respir Crit Care Med. 1996:153:218-24.

25. Gilliland FD, Berhane K, McConnell R, Gauderman WJ, Vora H, Rappaport EB, Avol E, Peters JM. Maternal smoking during pregnancy, environmental tobacco smoke exposure and childhood lung function. Thorax. 2000;55:271-6.

26. Stick SM, Burton PR, Gurrin L, Sly PD, Lesouef PN. Effects of maternal smoking during pregnancy and a family history of asthma on respiratory function in newborn infants. Lancet. 1996;348:1060-4.

27. Cook DG, Strachan DP. Health effects of passive smoking. 3. Parental smoking and prevalence of respiratory symptoms and asthma in school age children. Thorax. 1997;52:1081-94

28. Stocks J, Godfrey S, Beardsmore C, Bar-Yishay E, Castile R. Plethysmographic measurements of lung volume and airway resistance. ERS/ATS Task Force on Standards for Infant Respiratory Function Testing. European Respiratory Society/ American Thoracic Society. Eur Respir J. 2001;17:302-12.

29. Joad JP, Ji C, Kott KS, Bric JM, Pinkerton KE. In utero and postnatal effects of sidestream cigarette smoke exposure on lung function,

hyperresponsiveness, and neuroendocrine cells in rats. Toxicol Appl Pharmacol. 1995;132:63-71.

30. Difranza JR, Aligne CA, Weitzman M. Prenatal and postnatal environmental tobacco smoke exposure and children's health. Pediatrics. 2004;113(4 Suppl):1007-15.

31. Larcombe AN, Foong RE, Berry LJ, Zosky GR, Sly PD. In utero cigarette smoke exposure impairs somatic and lung growth in BALB/C mice. Eur Respir J. 2011;38:932-8.

32. U.S. Department of Health and Human Services. The Health Consequences of Involuntary Exposure to Tobacco Smoke: a Report of the Surgeon General. Atlanta: U.S. Department of Health and Human Services, Centers for Disease Control and Prevention, Coordinating Center for Health Promotion, National Center for Chronic Disease Prevention and Health Promotion, Office on Smoking and Health; 2006.
33. Foronjy RF, Mercer BA, Maxfield MW, Powell CA, D'Armiento J, Okada Y. Structural emphysema does not correlate with lung compliance: lessons from the mouse smoking model. Exp Lung Res. 2005;31:547-62.

34. Huang DW, Sherman BT, Lempicki RA. Systematic and integrative analysis of large gene lists using DAVID Bioinformatics Resources. Nat Protoc. 2009;4:44-57.

35. Noël A, Xiao R, Perveen Z, Zaman HM, Rouse RL, Paulsen DB, Penn AL Incomplete lung recovery following sub-acute inhalation of combustionderived ultrafine particles in mice. Part Fibre Toxicol. 2016;13:10.

36. Knudsen L, Weibel ER, Gundersen HJ, Weinstein FV, Ochs M. Assessment of air space size characteristics by intercept (chord) measurement: an accurate and efficient stereological approach. J Appl Physiol. 2010;108:412-21.

37. Mannino DM, Moorman JE, Kingsley B, Rose D, Repace J. Health effects related to environmental tobacco smoke exposure in children in the United States: data from the Third National Health and Nutrition Examination Survey. Arch Pediatr Adolesc Med. 2001:155:36-41.

38. National Center for Chronic Disease Prevention and Health Promotion (US) Office on Smoking and Health. The health consequences of smoking - 50 years of progress: a report of the Surgeon General. Atlanta: U.S. Department of Health and Human Services, Centers for Disease Control and Prevention, National Center for Chronic Disease Prevention and Health Promotion, Office on Smoking and Health; 2014.

39. Xiao R, Noel A, Perveen Z, Penn AL. In utero exposure to second-hand smoke activates pro-asthmatic and oncogenic miRNAs in adult asthmatic mice. Environ Mol Mutagen. 2016;57:190-9.

40. Herceg Z, Vaissiere T. Epigenetic mechanisms and cancer: an interface between the environment and the genome. Epigenetics. 2011;6:804-19.

41. Wang L, Yao J, Sun H, He K, Tong D, Song T, Huang C. MicroRNA-101 suppresses progression of lung cancer through the PTEN/AKT signaling pathway by targeting DNA methyltransferase 3A. Oncol Lett. 2017;13:329-38.

42. Husni RE, Shiba-Ishii A, liyama S, Shiozawa T, Kim Y, Nakagawa T, Sato T, Kano J, Minami Y, Noguchi M. DNMT3a expression pattern and its prognostic value in lung adenocarcinoma. Lung Cancer. 2016:97:59-65.

43. Fernandez AF, Huidobro C, Fraga MF. De novo DNA methyltransferases: oncogenes, tumor suppressor, or both? Trends Genet. 2012;28:474-9.

44. Boucherat O, Morissette MC, Provencher S, Bonnet S, Maltais F. Bridging Lung Development with Chronic Obstructive Pulmonary Disease. Relevance of Developmental Pathways in Chronic Obstructive Pulmonary Disease Pathogenesis. Am J Respir Crit Care Med. 2016;193:362-75.

45. Liu G, Cooley MA, Jarnicki AG, Hsu AC, Nair PM, Haw TJ, Fricker M, Gellatly $\mathrm{SL}$, Kim RY, Inman MD, et al. Fibulin-1 regulates the pathogenesis of tissue remodeling in respiratory diseases. JCI Insight. 2016;1:9.

46. Askew DJ, Silverman GA. Intracellular and extracellular serpins modulate lung disease. J Perinatol. 2008;28 Suppl 3:S127-35.

47. Elliot J, Carroll N, Bosco M, Mccrohan M, Robinson P. Increased airway responsiveness and decreased alveolar attachment points following in utero smoke exposure in the guinea pig. Am J Respir Crit Care Med. 2001;163:140-4.

48. Landau LI. Tobacco smoke exposure and tracking of lung function into adult life. Paediatr Respir Rev. 2008;9:39-43.

49. Stocks J, Dezateux C. The effect of parental smoking on lung function and development during infancy. Respirology. 2003;8:266-85.

50. Maritz GS, Harding R. Life-long programming implications of exposure to tobacco smoking and nicotine before and soon after birth: evidence for altered lung development. Int J Environ Res Public Health. 2011;8:875-98.

51. Wongtrakool C, Wang N, Hyde DM, Roman J, Spindel ER. Prenatal nicotine exposure alters lung function and airway geometry through alpha7 nicotinic receptors. Am J Respir Cell Mol Biol. 2012;46:695-702.

52. Boddy K, Dawes GS. Fetal breathing. Br Med Bull. 1975;31:3-7.

53. Nielsen $\mathrm{HC}$. Androgen receptors influence the production of pulmonary surfactant in the testicular feminization mouse fetus. J Clin Invest. 1985; 76:177-81.

54. Torday JS, Nielsen HC. The sex difference in fetal lung surfactant production. Exp Lung Res. 1987;12:1-19.

55. Carey MA, Card JW, Voltz JW, Germolec DR, Korach KS, Zeldin DC. The impact of sex and sex hormones on lung physiology and disease: lessons from animal studies. Am J Physiol Lung Cell Mol Physiol. 2007;293:L272-8.

56. Hsu HH, Chiu YH, Coull BA, Kloog I, Schwartz J, Lee A, Wright RO, Wright RJ. Prenatal particulate air pollution and asthma onset in urban children. Identifying sensitive windows and sex differences. Am J Respir Crit Care Med. 2015;192:1052-9.

57. Wynder EL, Muscat JE. The changing epidemiology of smoking and lung cancer histology. Environ Health Perspect. 1995;103 Suppl 8:143-8. 
58. Devesa SS, Bray F, Vizcaino AP, Parkin DM. International lung cancer trends by histologic type: male:female differences diminishing and adenocarcinoma rates rising. Int J Cancer. 2005;117:294-9.

59. Thun MJ, Henley SJ, Burns D, Jemal A, Shanks TG, Calle EE. Lung cancer death rates in lifelong nonsmokers. J Natl Cancer Inst. 2006;98:691-9.

60. Carey MA, Card JW, Voltz JW, Arbes Jr SJ, Germolec DR, Korach KS, Zeldin DC. It's all about sex: gender, lung development and lung disease. Trends Endocrinol Metab. 2007;18:308-13.

61. Sennhauser FH, Kuhni CE. Prevalence of respiratory symptoms in Swiss children: is bronchial asthma really more prevalent in boys? Pediatr Pulmonol. 1995;19:161-6.

62. Lichtenstein P, Svartengren M. Genes, environments, and sex: factors of importance in atopic diseases in 7-9-year-old Swedish twins. Allergy. 1997;52:1079-86.

63. SIDRIA (Italian Studies on Respiratory Disorders in Childhood and the Environment). Asthma and respiratory symptoms in 6-7 yr old Italian children: gender, latitude, urbanization and socioeconomic factors. Eur Respir J. 1997;10:1780-6.

64. Mandhane PJ, Greene JM, Cowan JO, Taylor DR, Sears MR. Sex differences in factors associated with childhood- and adolescent-onset wheeze. Am J Respir Crit Care Med. 2005;172:45-54.

65. Almqvist C, Worm M, Leynaert B. Impact of gender on asthma in childhood and adolescence: a GA2LEN review. Allergy. 2008;63:47-57.

66. Cook DG, Strachan DP, Carey IM. Health effects of passive smoking. 9. Parental smoking and spirometric indices in children. Thorax. 1998;53:884-93.

67. Hoo AF, Henschen M, Dezateux C, Costeloe K, Stocks J. Respiratory function among preterm infants whose mothers smoked during pregnancy. Am J Respir Crit Care Med. 1998;158:700-5.

68. Strachan DP, Cook DG. Health effects of passive smoking. 1. Parental smoking and lower respiratory illness in infancy and early childhood. Thorax. 1997;52:905-14.

69. Cook DG, Strachan DP. Health effects of passive smoking-10: Summary of effects of parental smoking on the respiratory health of children and implications for research. Thorax. 1999;54:357-66.

70. Li YF, Gilliland FD, Berhane K, McConnell R, Gauderman WJ, Rappaport EB, Peters JM. Effects of in utero and environmental tobacco smoke exposure on lung function in boys and girls with and without asthma. Am J Respir Crit Care Med. 2000;162:2097-104.

71. Stocks J, Hislop A, Sonnappa S. Early lung development: lifelong effect on respiratory health and disease. Lancet Respir Med. 2013;1:728-42.

72. McEvoy CT, Schilling D, Clay N, Jackson K, Go MD, Spitale P, Bunten C, Leiva M, Gonzales D, Hollister-Smith J, et al. Vitamin C supplementation for pregnant smoking women and pulmonary function in their newborn infants: a randomized clinical trial. JAMA. 2014;311:2074-82.

73. Spindel ER, McEvoy CT. The role of nicotine in the effects of maternal smoking during pregnancy on lung development and childhood respiratory disease. Implications for dangers of E-cigarettes. Am J Respir Crit Care Med. 2016;193:486-94.

74. Hayatbakhsh MR, Sadasivam S, Mamun AA, Najman JM, Williams GM, O'Callaghan MJ. Maternal smoking during and after pregnancy and lung function in early adulthood: a prospective study. Thorax. 2009;64:810-4.

75. Tarantini L, Bonzini M, Apostoli P, Pegoraro V, Bollati V, Marinelli B, Cantone L, Rizzo G, Hou L, Schwartz J, et al. Effects of particulate matter on genomic DNA methylation content and iNOS promoter methylation. Environ Health Perspect. 2009;117:217-22.

76. Hollingsworth JW, Maruoka S, Boon K, Garantziotis S, Li Z, Tomfohr J, Bailey N, Potts EN, Whitehead G, Brass DM, et al. In utero supplementation with methyl donors enhances allergic airway disease in mice. J Clin Invest. 2008;1 18:3462-9.

77. Breton CV, Byun HM, Wenten M, Pan F, Yang A, Gilliland FD. Prenatal tobacco smoke exposure affects global and gene-specific DNA methylation. Am J Respir Crit Care Med. 2009;180:462-7.

78. Durham AL, Wiegman C, Adcock IM. Epigenetics of asthma. Biochim Biophys Acta. 2011;1810:1103-9.

79. Sun C, Burgner DP, Ponsonby AL, Saffery R, Huang RC, Vuillermin PJ, Cheung M, Craig JM. Effects of early-life environment and epigenetics on cardiovascular disease risk in children: highlighting the role of twin studies. Pediatr Res. 2013;73:523-30.

80. Feinberg AP, Vogelstein B. Hypomethylation distinguishes genes of some human cancers from their normal counterparts. Nature. 1983;301:89-92.

81. Chen RZ, Pettersson U, Beard C, Jackson-Grusby L, Jaenisch R. DNA hypomethylation leads to elevated mutation rates. Nature. 1998;395:89-93.
82. Herman JG, Jen J, Merlo A, Baylin SB. Hypermethylation-associated inactivation indicates a tumor suppressor role for p15INK4B. Cancer Res. 1996;56:722-7.

83. Reu FJ, Leaman DW, Maitra RR, Bae SI, Cherkassky L, Fox MW, Rempinsky DR, Beaulieu N, Macleod AR, Borden EC. Expression of RASSF1A, an epigenetically silenced tumor suppressor, overcomes resistance to apoptosis induction by interferons. Cancer Res. 2006;66:2785-93.

84. Jia Y, Li P, Fang L, Zhu H, Xu L, Cheng H, Zhang J, Li F, Feng Y, Li Y, et al. Negative regulation of DNMT3A de novo DNA methylation by frequently overexpressed UHRF family proteins as a mechanism for widespread DNA hypomethylation in cancer. Cell Discov. 2016;2:16007.

85. Gao Q, Steine EJ, Barrasa MI, Hockemeyer D, Pawlak M, Fu D, Reddy S, Bell GW, Jaenisch R. Deletion of the de novo DNA methyltransferase Dnmt3a promotes lung tumor progression. Proc Natl Acad Sci U S A. 2011;108:18061-6.

86. Raddatz G, Gao Q, Bender S, Jaenisch R, Lyko F. Dnmt3a protects active chromosome domains against cancer-associated hypomethylation. PLoS Genet. 2012:8:e1003146.

\section{Submit your next manuscript to BioMed Central and we will help you at every step:}

- We accept pre-submission inquiries

- Our selector tool helps you to find the most relevant journal

- We provide round the clock customer support

- Convenient online submission

- Thorough peer review

- Inclusion in PubMed and all major indexing services

- Maximum visibility for your research

Submit your manuscript at www.biomedcentral.com/submit
Biomed Central 